\title{
Hydrogen Retention Properties of SiC/SiC Composites as Plasma Facing Material of Fusion Reactor*
}

\author{
Yuji NOBUTA*1, Yuji YAMAUCHI*1, Tomoaki HINO*1, Ho-Jun CHO*2 and Han-Ki YOON*2 \\ ${ }^{*}{ }_{1}$ Department of Nuclear Engineering, Hokkaido University, Kita-ku, Sapporo, 060-8628 Japan \\ ${ }^{* 2}$ Department of Mechanical Engineering, Dong-Eui University, 995 Eomgwangno, Busanjin-gu, BUSAN 614-714, KOREA
}

(Received November 6, 2010, Accepted January 14, 2011)

In order to examine the deuterium retention properties of $\mathrm{SiC} / \mathrm{SiC}$ compositess, the deuterium ion irradiation was conducted followed by a thermal desorption spectroscopymeasurement. The deuterium retained was desorbed in forms of HD, $\mathrm{D}_{2}, \mathrm{HDO}$, $\mathrm{CD}_{4}$ and $\mathrm{C}_{2} \mathrm{D}_{4}$. The ratio of the amount of desorbed hydrocarbons to the total amount of retained deuterium was approximately $6 \%$, which is much smaller, compared with the case of carbon material. Namely, we confirmed that the chemical erosion of $\mathrm{SiC} / \mathrm{SiC}$ composites isquite small. In the $\mathrm{D}_{2}$ desorption spectra, two desorption peaks appeared. The lower and higher temperatures peaks were regarded to be due to detrappings of Si-D and C-D bonds, respectively. The ratio of deuterium amount desorbed at highertemperature decreased with increase of the deuterium fluence. This behavior could be explained that the carbon content at thesurface is reduced by the selective sputtering due to deuteriumions.

\section{Introduction}

$\mathrm{SiC}$ fiber reinforced $\mathrm{SiC}$ matrix $(\mathrm{SiC} / \mathrm{SiC})$ composites is a candidate material for plasma-facing material of a fusion reactor and structural components due to its low induced activation, low atomic number, high thermal shock resistance and good thermal conductivity and so on $^{1,2)}$. In magnetic fusion devices, although hydrogen ions are confined by a magnetic field in a core plasma, a charge exchange reaction occurs between energetic hydrogen ions and hydrogen neutral particles at a plasma edge, and energetic hydrogen particles are implanted into the plasma-facing materials ${ }^{3,4}$. If the amount of retained hydrogen in plasma-facing walls becomes large, the hydrogen is released into the plasma during the discharge, leading to an enhancement of hydrogen recycling. Hydrogen release from the walls can lead to an uncontrolled density rise and to an deterioration of plasma confinement time of core plasma. In a DT fusion reactor, tritium inventory in the vacuum vessel is limited from the point of view of safety, and influence operational schedule ${ }^{5)}$. For these reasons, hydrogen retention behavior of plasma-facing materials needs to be investigated.

In the present study, we examined the desorption behavior of hydrogen retained in a $\mathrm{SiC} / \mathrm{SiC}$ composites after deuterium ion irradiation using an ECR ion apparatus.

\section{Experiments}

The samples used in this study were produced by a liquid phase sintering (LPS) process ${ }^{6}$. In the LPS process, $\mathrm{SiC} / \mathrm{SiC}$ composites were prepared from fiber preforms by a slurry infiltration technique, in which a mixture with $\mathrm{SiC}$ and sintering additives $\left(\mathrm{Al}_{2} \mathrm{O}_{3}\right.$ and $\left.\mathrm{Y}_{2} \mathrm{O}_{3}\right)$ particles

\footnotetext{
* Presented as a contributed talk at the 51st annual symposium of
} the Vacuum Society of Japan, Nov. 4, 2010 was impregnated into the $\mathrm{SiC}$ fabric structure. These prepared preforms were sintered at $2073 \mathrm{~K}$ with an applied pressure of $20 \mathrm{MPa}$.

The size of the sample were $10 \times 10 \times 1 \mathrm{~mm}$. Before the deuterium ion irradiation, the samples were degassed at $1273 \mathrm{~K}$ for $30 \mathrm{~min}$. The deuterium ion irradiation followed by a thermal desorption spectroscopy (TDS) measurement ${ }^{7)}$, were conducted in the ECR ion irradiation apparatus ${ }^{8)-10)}$. An average flux during the irradiation was of the order of $\sim 10^{14} / \mathrm{cm}^{2}$, which was estimated from the sample current. During the ion irradiation, the sample temperature was room temperature. The ion fluence was varied from $0.2 \times 10^{18} / \mathrm{cm}^{2}$ to $5 \times 10^{18} / \mathrm{cm}^{2}$. After the irradiation, the sample was extracted from ECR apparatus and put in the TDS apparatus. The background pressure during the TDS measurement was of the order of $10^{-7} \mathrm{~Pa}$. The sample was heated linearly from room temperature (RT) to $1273 \mathrm{~K}$ with a heating rate of $50 \mathrm{~K} / \mathrm{min}$. During the sample heating, the desorption rate of gases desorbed from the sample were measured by a quadruple mass spectrometer (QMS). The amounts of desorbed gases were quantitatively obtained by timeintegrating the desorption rate. In order to examine a change of the surface composition caused by deuterium ion irradiation, depth profiles of atomic composition before and after irradiation was analyzed by means of $\mathrm{Au}-$ ger electron spectrometry.

\section{Results and discussion}

Figure 1 shows the depth profiles of atomic composition of the $\mathrm{SiC} / \mathrm{SiC}$ composites before deuterium ion irradiation (Fig. 1(a)) and after the irradiation (Fig. 1 (b)). After the irradiation, the atomic composition of carbon decreased, and that of silicon increased. Since the mass of carbon atom is smaller than that of silicon atom, carbon atom could be more easily sputtered than silicon atom by physical sputtering process. In addition, carbon is sputtered not only by physical sputtering process but 
(a)

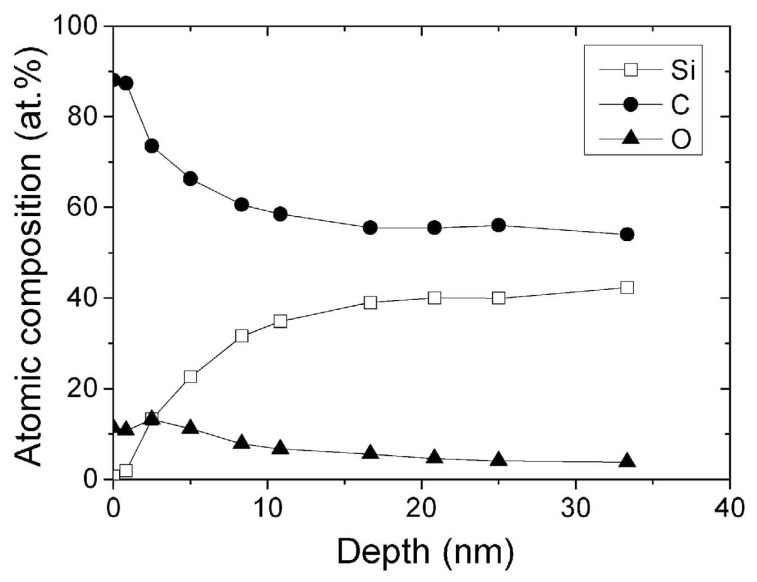

(b)

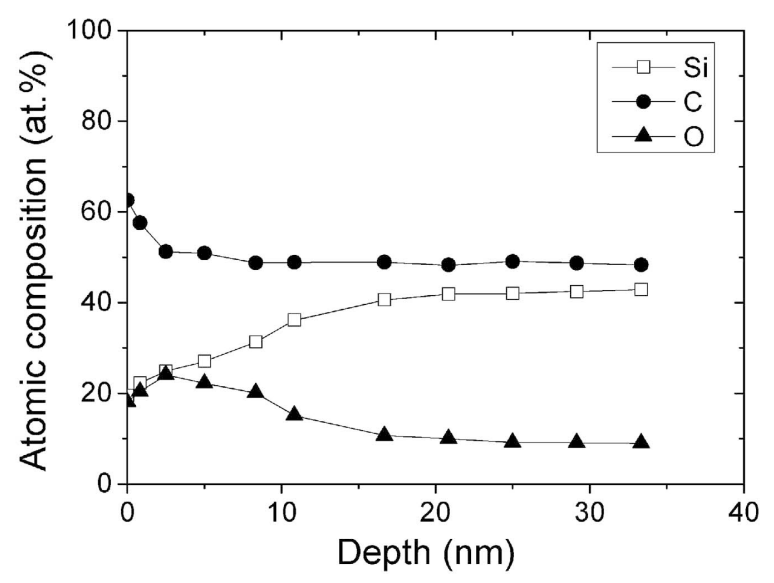

Figure 1 Depth profiles of atomic composition of SiC/SiC compositess before deuterium ion irradiation (a) and after irradiation (b).

chemical sputtering process ${ }^{5)}$. This might be a possible reason for the reduction of atomic composition of carbon after the irradiation.

Figure 2 shows the thermal desorption spectra of $D_{2}$ after deuterium ion irradiation at various fluences. The desorption spectra of $\mathrm{D}_{2}$ has two main peaks at around $1000 \mathrm{~K}$ and $1200 \mathrm{~K}$. Yamauchi et al. have reported that thermal desorption spectra of $\mathrm{H}_{2}$ for a $\mathrm{SiC}$ converted graphite material after energetic hydrogen ion irradiation showed two desorption peaks and that the lower and higher temperature peaks were responsible for the bonding of $\mathrm{Si}-\mathrm{C}$ and $\mathrm{C}-\mathrm{D}$, respectively ${ }^{10)}$. Therefore, the desorption peak at lower and higher temperature in this study would be also responsible for the bonding of $\mathrm{Si}-\mathrm{C}$ and $\mathrm{C}-\mathrm{D}$, respectively.

As can be in Fig. 2, the desorption rate of the lower temperature peak increased with the deuterium fluence and the desorption rate of higher temperature peak was almost constant at each fluences. Figure 3 shows the ratio of the amounts of desorbed $\mathrm{D}_{2}$ at the lower and the higher temperature peaks, which were estimated from a

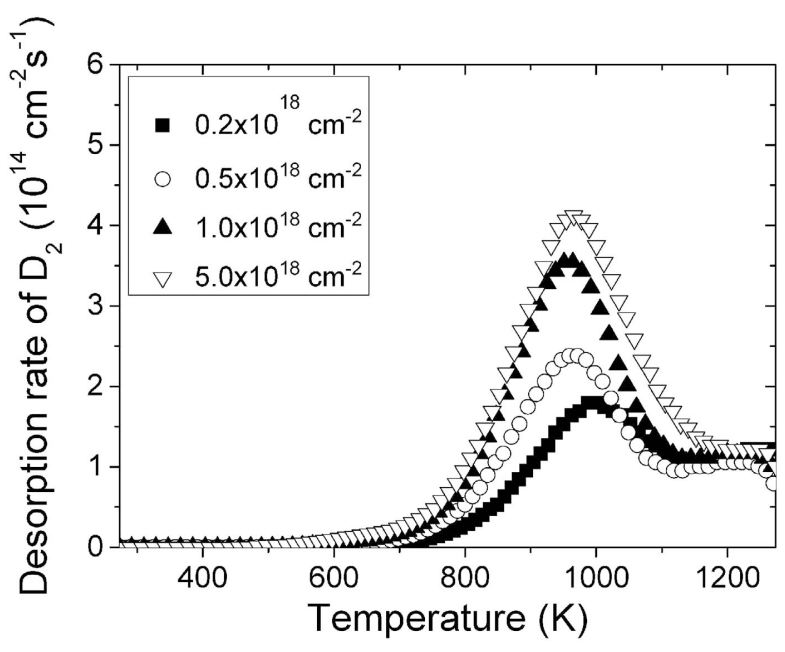

Figure 2 Thermal desorption spectra of $\mathrm{D}_{2}$ after deuterium ion irradiation at various fluences.

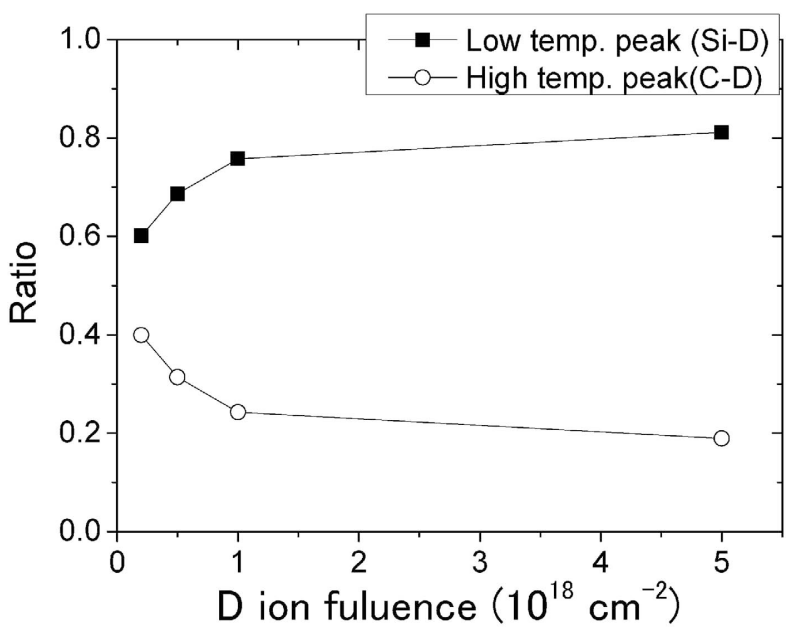

Figure 3 Amounts of desorbed $\mathrm{D}_{2}$ at the lower and higher temperatures estimated from peak separation.

peak separation. At the fluence of $0.2 \times 10^{18} / \mathrm{cm}^{2}$, the ratios of desorbed amounts of deuterium at the lower and higher temperatures peaks were 0.6 and 0.4 , respectively. The ratio of desorbed amount at the lower temperature peak increased with increasing in the fluence, and became 0.8 at the fluence of $5.0 \times 10^{18} / \mathrm{cm}^{2}$. As shown in Fig. 1, the atomic composition of silicon increased and that of carbon decresed with increasing in the deuterium ion fluence. That corresponds to the increase of the ratio of desorbed amount at lower temperature peak.

Figure 4 shows the desorbed amount of D-containing gases as a function of deuterium ion fluence. The deuterium retained in the $\mathrm{SiC} / \mathrm{SiC}$ composites was desorbed in the form of $\mathrm{D}_{2}, \mathrm{HD}, \mathrm{HDO}, \mathrm{CD}_{4}$ and $\mathrm{C}_{2} \mathrm{D}_{4}$. The total amount of desorbed deuterium seemed to be roughly saturated at the fluence of $5.0 \times 10^{18} / \mathrm{cm}^{2}$. The total amount of retained deuterium at the fluence of $5.0 \times 10^{18}$ $/ \mathrm{cm}^{2}$ was $5.1 \times 10^{17} / \mathrm{cm}^{2}$. This value is about $15 \%$ smaller than that of a $\mathrm{SiC}$ converted graphite material after hydrogen irradiation ${ }^{9}$. The bulk density of the $\mathrm{SiC}$ $/ \mathrm{SiC}$ composites used in this study, $3.1 \mathrm{~g} / \mathrm{cm}^{3}$, was 


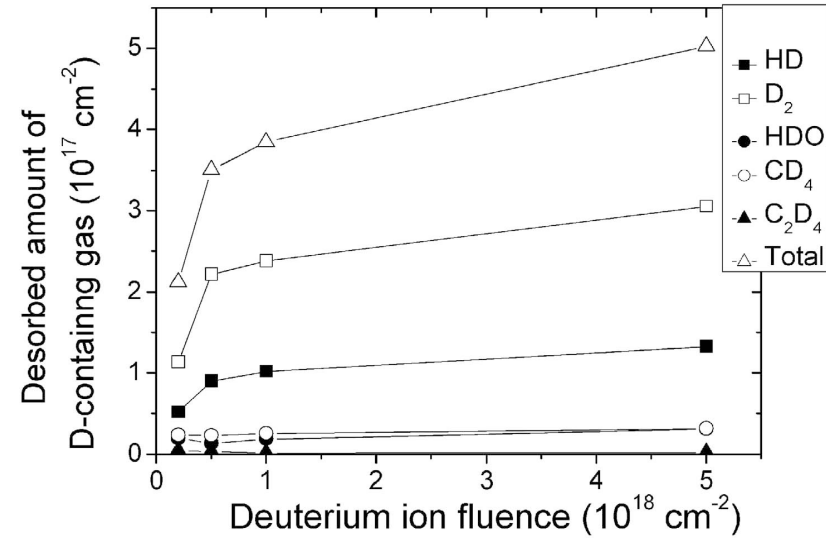

Figure 4 Desorbed amount $\mathrm{f}$ D-containing gases as a function of deuterium fluence.

higher than that of the $\mathrm{SiC}$ converted graphite, $1.9 \mathrm{~g} /$ $\mathrm{cm}^{3}$. Therefore, the $\mathrm{SiC}$ converted graphite would have more amorphous structure and have more large number of trapping site (dangling bond), compared with the SiC / $\mathrm{SiC}$ composites. This would be one of the possible reason for the difference of the amounts of retained deuterium.

A ratio of the desorbed amount of hydrocarbons $\left(\mathrm{CD}_{4}\right.$ and $\left.\mathrm{C}_{2} \mathrm{D}_{4}\right)$ to the total amount of desorbed deuterium is important, especially for carbon-based materials, from the point of view of the chemical sputtering of carbon materials. At the fluence of $5.0 \times 10^{18} / \mathrm{cm}^{2}$, the ratio was approximately $6.4 \%$, which is a little higher than that of $\mathrm{SiC}$ converted graphite $(2.3 \%)^{10}$ ). In the case of graphite, the total amount of desorbed hydrogen at the fluence of $5.0 \times 10^{18} / \mathrm{cm}^{2}$ was $6.7 \times 10^{17} / \mathrm{cm}^{2}$, and the amount of hydrogen desorbed as hydrocarbons was 1.7 $\times 10^{17} / \mathrm{cm}^{2}$, which corresponds to $25 \%$ of the total amount ${ }^{10)}$. It indicates that the chemical sputtering yield of the $\mathrm{SiC} / \mathrm{SiC}$ composites under hydrogen irradiation is expected to be much smaller compared with that of graphite.

\section{Summary}

In this study, hydrogen retention properties were investigated with thermal desorption spectroscopy following deuterium ion irradiation. Two peaks were observed in the desorption spectra of $\mathrm{D}_{2}$. The higher and lower desorption peaks were thought to be responsible for the detrapping of $\mathrm{Si}-\mathrm{D}$ and $\mathrm{C}-\mathrm{D}$ bond, respectively. The desorption rate of the lower temperature peak increased with deuterium ion fluence. On the other hand, the desorption rate of the higher temperature peaks were almost the same at each ion fluence. After deuterium ion irradiation, the atomic composition of $\mathrm{Si}$ increased and that of carbon decreased, which would be a reason for the increase in desorption from $\mathrm{Si}-\mathrm{D}$ bond. A ratio of amount of desorbed hydrocarbons to total desorbed amount was $6.2 \%$, that is much smaller than that the case of pure carbon ${ }^{10)}$. It suggests that the $\mathrm{SiC} / \mathrm{SiC}$ composites could reduce a chemical sputtering compared with pure carbon material.

\section{References}

1) Steven J. Zinkle: Fus. Eng. Des., 74 (2005) 31.

2) R. Andreani, E. Diegele, W. Gulden, R. Lässer, D. Maisonnier, D. Murdoch, M. Pick, Y. Poitevin and The EFDA Team Garching: Fus. Eng. Des, 81 (2006) 25.32.

3) G. Staudenmaier and W. R. Wampler: J. Nucl. Mater., 162-164 (1989) 414.

4) T. Hirai, T. Fujiwara, K. Tokunaga, N. Yoshida, S. Itoh and TRIAM Group: J. Nucl. Mater., 290-293 (2001) 94.

5) G. Federici, C. H. Skinner, J. N. Brooks, J. P. Coad, C. Grisolia, A. A. Haasz, A. Hassanein, V. Philipps, C. S. Pitcher, J. Roth, W. R. Wampler and D. G. Whyte: Nuclear Fusion, 41 (2001) 1967.

6) Lance L. Snead, T. Nozawa, Y. Katoh, Thak-Sang Byun, S. Kondo and D. A. Petti: J. Nucl. Mater., 371 (2007) 329.

7) P. A. Redhead: Vacuum 12 (1962) 203.

8) Y. Yamauchi, T. Hino, Y. Hirohata and T. Yamashina: Vacuum 47 (1996) 973.

9) Y. Yamauchi, T. Hino, K. Koyama, Y. Hirohata and T. Yamashina: J. Nucl. Mater, 241-243 (1997) 1016.

10) Y. Yamauchi, Y. Hirohata and T. Hino: Fus. Eng. Des., 39-40 (1998) 427. 